\title{
INTERVIEW WITH WOLFGANG DREYBRODT „TO UNDERSTAND THE ENVIRONMENT, WHICH GAVE SO MUCH ADMIRATION AND ADVENTURE“
}

\author{
conducted by IVO LUČIĆ
}

The series of interviews continues with Wolfgang Dreybrodt, an emeritus professor of experimental physics at the University of Bremen. As his student and a friend I am particularly happy that his unique life story, that brought him into the karst research, is now published in our journal. His book "Processes in Karst systems", published by Springer in 1988, brought a new view on karst based on the basic principles of physics and chemistry. Numerous publications on dissolution kinetics, speleogenesis, growth of speleothems and related isotopic evolution, that he has published with his coworkers, are presenting important foundations of our current understanding of karst systems. Seven years after being retired, Wolfgang is still active and devoted to high scientific and ethical standards as he has ever been.

Franci Gabrovšek, Editor

How did you acquaint yourself with karst and became close to it? Have you met with karst when you were still a child or when you've already become a scientist?

I was born in the mountains of the Erzgebirge, not particularly limestone, but with a lot of outcrops of basaltic rocks, which form little exciting canyons, similar to those in caves but without roofs. And there are the old abandoned silver mines. So rocks and dark rooms attracted our attention, when we were children in the age between 6 to 11 years. When I was eleven we left the GDR and went to West Germany for a better and a free life. This was not easy. In a way we were immigrants, we had to fight until we had established a new life. There simply was no time for caves living in areas without caves. I studied physics and worked in Frankfurt, Cambridge Massachusetts at MIT, and then in Stuttgart, where karst and caves were close. This raised my interest again and I started to visit caves in the Schwäbische Alb, mostly show caves, but also some small wild caves. There was not much time, however, because a career as a scientist in a highly competitive Max-Planck-Institute does not give you much time, when you have a family with two children.

In 1974 I went to the University of Bremen as professor for experimental physics. This was a newly founded university, which tried to realize some of the new ideas, the 68-movement had put forward. I went there naively that these ideas would help to improve the hierarchical system of German universities. What I

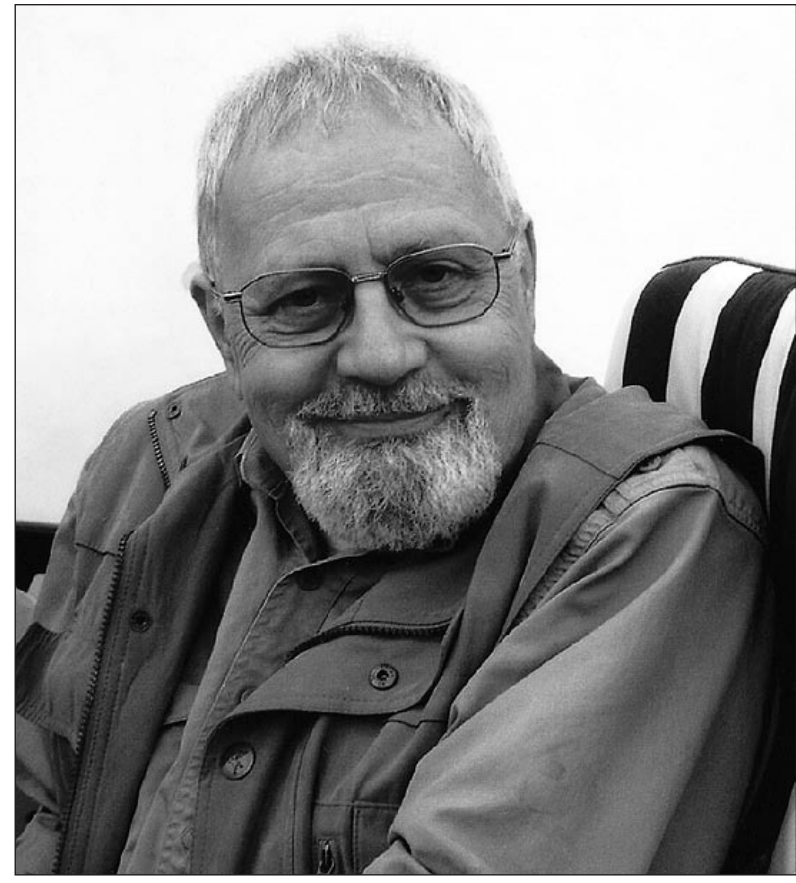

1: Wolfgang Dreybrodt portrait in 2011.

found was an incredible realm of ignorance and intolerance, isolating everybody, who did not follow the main ideas of this Reform- Universität. I was regarded to be politically left in my old environment, now I found myself as extreme conservative right wing, without having changed my views at all. In this environment it was not 
possible to do any science in reasonable cooperation. So the next years were a political fight for the reasonable and responsible education of students in the subject they studied, clearly in opposition to the ruling Social Democratic Party in Bremen and the university supported by it. The result was social and personal isolation, bashing and bullying at work, particularly in my lectures. I needed to find something to endure this. That is where karst comes in. I started to do caving in the Harz mountains, in the Sauerland, with muddy narrow caves at that time and I learned the basic techniques, how to move in caves. My son Jörg accompanied me. Now he organizes caving expeditions in remote areas of Laos and Myanmar. My wife Marion, although she accompanied me in some caves had many lone weekends in Bremen afraid that some accident could happen. But nevertheless she supported me and without her help things might have become entirely different. So she shares merits with me and I am grateful to her.

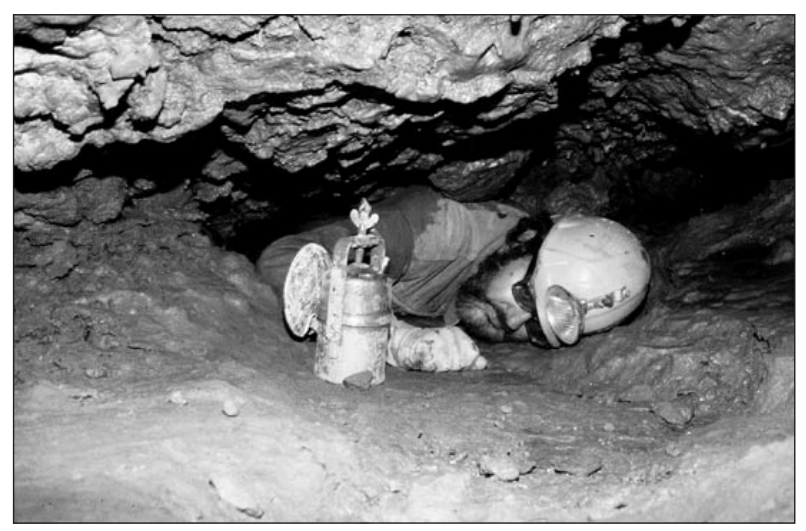

2: Wolfgang Dreybrodt squeezing through the "eye of a needle", an extremely narrow passage in the Kreuzhöhle near Iserlohn. Note the equipment of German amateur cavers in the early eighties.

Interested in caves I started to read books about caving expeditions. Those of Herbert W. Franke and Alfred Bögli had also some ideas on growth of stalagmites and evolution of caves by mixing corrosion. This inspired me to join this field. I could do this by myself and was not depending on support by a hostile intellectual environment of the University of Bremen. The first paper dealt with precipitation rates and the growth of stalagmites. Others looked for dissolution rates and cave evolution by mixing corrosion. They all were accepted for publication in Chemical Geology. For some reasons our library had a good collection of speleological literature and a librarian, who supported me. So I could find out what happened internationally.
How did dealing with karst influence your scientific life and thinking?

I started my scientific career as an experimental physicist with a sound theoretical background. Physics is a rather simple science because mostly it deals with relatively basic well-defined systems. Compared to a biological molecule, like haemoglobin, on which I worked later, even the most complex electronic device build from semiconductor materials is fairly simple. So in basic physics questions are clear and the answers to them can be verified or falsified experimentally. This structure of discipline of course influences the way of thinking and how to deal with problems in physics.

Things become much more complicated if one works with more complex systems like the surface of limestone and dissolution or precipitation acting to it. Physically this is an incredibly dirty system. In the first approach you have to do experiments, improve them to get rid of many sources of error. You have to deal with hydrodynamics, kinetics of chemical reactions, molecular diffusion. Many parts of physics and chemistry come together and answers are no longer so easy to find. So up to now there is still a lot of research on dissolution and precipitation of carbonate rocks. And there are many applications, e.g. sequestration of $\mathrm{CO}_{2}$ by conversion into $\mathrm{CaCO}_{3}$.

All this in mind, my self-confidence on what we had done became somewhat limited and consequently we continued to do experiments on the dissolution and precipitation kinetics. The last paper we published in 2007 and deals with dissolution of calcite in solutions of high undersaturation, as they occur on rocks exposed to rain. This has some relevance on limestone denudation, formation of karren, and weathering of buildings constructed from limestone.

Once we were sufficiently sure we applied this knowledge to model the evolution of caves taking into account what we knew. I realized very early that one couldn't model a special cave. What we were looking for was to find out, which processes are important in the formation of karst. I am sure we discovered a few, but I also think we are still missing many.

But even with what we used we found that just adding some new processes, e.g. mixing corrosion produces new parameters and the models become more and more complicated. So my opinion on modelling changed. Nowadays models are widely used. Of course they are necessary, especially where you cannot conduct experiments as in many fields of Earth Science. But we should keep in mind that extreme care has to be taken, when using such models to predict future events, like climatic change and global warming. Dealing with all the uncertainties in the field of karst has shown me that I should 
highly respect natural laws and how they are connected, and how limited our knowledge is.

This ongoing experience has made me humble. One consequence is: You never should consider only arguments in favour of your ideas and opinion, but one has to take seriously into account all arguments undermining the own results. Considering all carefully one should present the outcome without hiding any of the counter arguments.

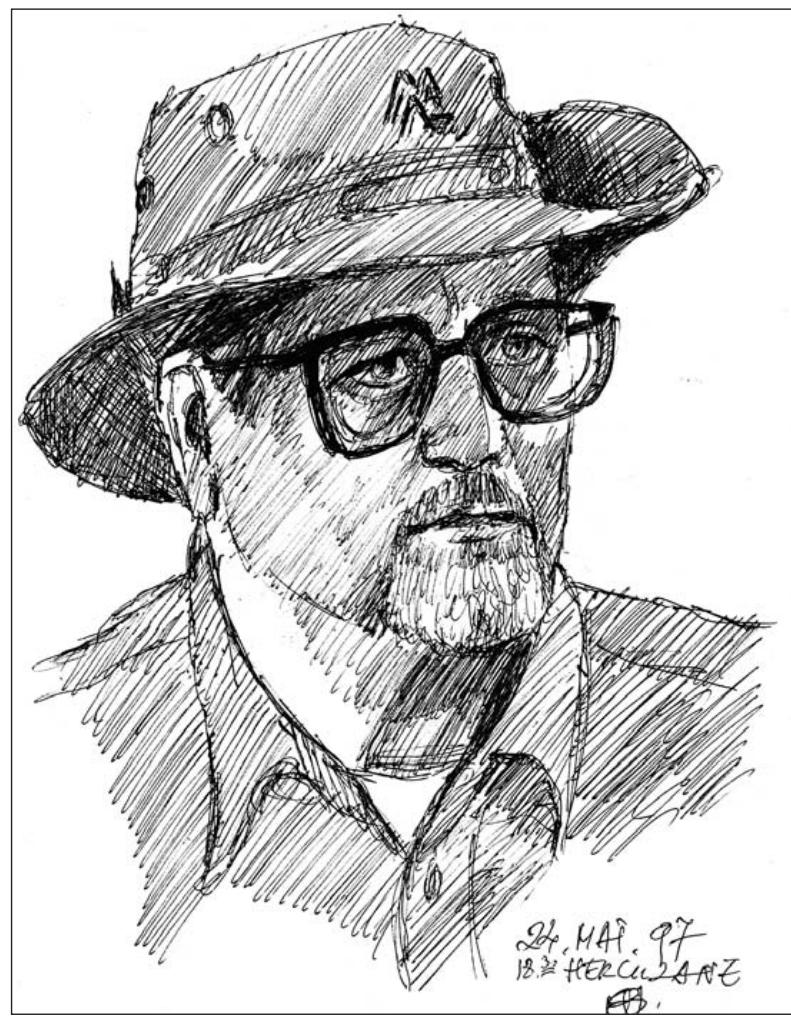

3: Wolfgang Dreybrodt. Drawing of a local artist in Băile Herculane, Romania, 1997.

I become angry when I see nowadays many scientists overstating their results for what reason so ever, maybe to obtain further funding. Some research on stalagmites as climate proxies is an example in karst science. Even worse, if science is used to foster political influence as is widely done in the discussion about anthropogenic global warming. To tell people that the models are solely based on the laws of physics and are therefore to be taken highly realistic and reliable without stating the limits of data to calibrate them and without pointing out the limitations in the feedback mechanisms is simply unethical scientific behaviour, or may become almost criminal depending on the issue. In summary dealing with complex natural systems has changed my thinking considerably from that which I had when I was young, dealing only with simple physics. Maybe this would still determine much of my attitude nowadays if I had not had the experience in karst, both in science and in reality.

There is another part of my personal life, which has been influenced by karst. This is the direct contact with many people internationally, the opportunity to see caves and surface karst in many places of the world and to discuss these features. Although nowadays my visit to caves is limited to the very easy ones, I am still fascinated by this world, and remembering what I have seen and experienced.

You have been unknown to the scientific community that dealt with the karst? How did you meet them? How have you been accepted?

Will B. White and Art Palmer in the US were dealing with similar problems on speleogenesis, which I found highly interesting. I owe them a lot. After some time it was clear that experiments were needed instead of pure theoretical reasoning. In the meantime the worst part of the Cultural Revolution at the university had come to an end. My first PhD-student was Dieter Buhmann and we started to do experiments on limestone dissolution and precipitation and also to develop a comprehensive theory. Later Liu Zaiha continued that work and contributed significantly to the understanding of dissolution and precipitation of calcite in turbulent flow. This all was the breakthrough. I got financial support from the German Research Foundation (DFG). All our lab work was supported by Jürgen Lauckner, an ingenious technician. His excellent work in designing und building experimental setups contributed significantly to our work. The idea to write the book, "Karst Processes" was suggested to Wolfgang Engel, the editor of the Springer Verlag by Prof. Usdowski on a nice evening in the wine cellar of a monastery during a scientific meeting "In vino veritas". Completely unknown I had entered the scene quite successfully. I could now establish international contacts to leading karst researchers in the USA, Art Palmer, Will White and to Derek Ford in Canada, to Yuan Daoxian in China and later to the Karst Research Institute in Postojna, Slovenia. As somebody not known to any of them, because I just started to become integrated into the international karst community. I visited them in the US and they showed karst and caves to me in a cordial and friendly way. I am very grateful to all of them. Their support was invaluable for me and helped to attract international students to Bremen, the most important, my team, from the "Balkan" Franci Gabrovšek and Douchko Romanov.

\section{POLITICS}

Political interference in science has indirectly directed you to the karst. What is your view on the relationship between science and politics? 
During my active time at the university I got heavily involved in politics trying to keep political ideologies, at that time Marxist and socialistic, out of teaching and out of science. This was hard fighting. I later was awarded for that by a Verdienstmedaille des Deutschen Bundestags, 1989. I know well interactions between science and politics. My topics in science, molecular biophysics on haemoglobin and porphyrines and what I did in karst science were sufficiently neutral and after 1985 the ideological concept had failed. To get recognition the university needed successful scientists and I did not have a problem with funding. Severe problems arise when scientists give advice to policy makers, not only by presenting founded knowledge, but also less founded projections to the future. The debate on manmade global warming and its icon, the hockey stick graph, is a good example. In this case the mutual interaction of politics, science and funding can corrupt the credibility of both scientists and politicians as the controversy on "climate gate" has shown.

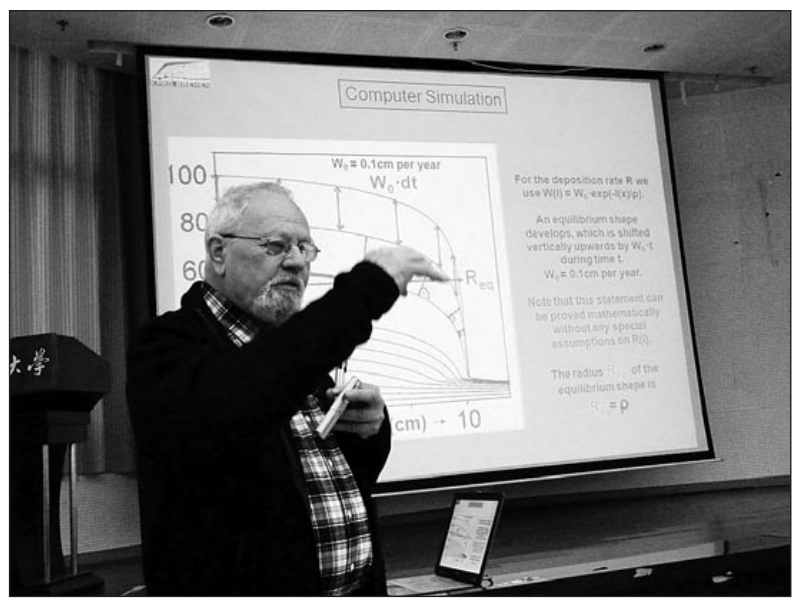

4: Wolfgang Dreybrodt presenting a lecture on stalagmites in Chongqing, China, December 2010.

\section{KARSTOLOGY}

How do you see and explain karstology and what is the most important for its development?

I personally do not like this word very much. I would prefer science of karst. It describes all phenomena found in karst regions. These are terrains dominated by soluble rocks mostly carbonates and gypsum. So first leading ideas arose from descriptive work by geographers, geomorphologists and geologists. There were also biologists studying cave animals and their evolution. All this was not very much connected and different views of karst, depending on the specific areas, where researchers lived, developed. So karst in Kentucky for instance, with flat thickly bedded limestone is different from karst in the Alps. There was also a language barrier. The English literature was little perceived by French and Italians and visa versa.

The first pioneering step to understand karst from basic principles was taken by Alfred Bögli, who tied principles of physics and chemistry to karst phenomena and his book Karsthydrographie und physische Speläologie published in German first was a milestone to this philosophy. My problem in karst science at this time was that there were too many general and undefined terms, like fracture penetrable by water, or widening of fractures by aggressive water etc, etc. One recent term, which I like especially, is inception horizon. All this must be quantified and put into the context of physics and chemistry, which govern karst processes. This new concept was developed in the last thirty years. Nowadays hydrological engineers have learned that groundwater in karst behaves differently than that in porous media. The need for groundwater management in karstic rocks has attracted a lot of researchers, mainly engineers to model karst aquifers, to deal with problems of salt-water intrusion in carbonate islands and coastal areas, or to understand the relation of sinkholes to manmade changes of hydrologic boundary conditions.

Work in all these new fields needs first good basic knowledge in the discipline, which is applied, and also the capability to understand the problems from the view of geology of karst. In my opinion this will be the way science of karst will develop in the future. So geologists should have a good basic knowledge of physics, chemistry and mathematics, which must be a part of their education. Engineers, physicists, chemists involved in karst must be ready to learn about geology to at least the extent, which enables them to have a good idea, what they are dealing with.

For future education of scientists working on all aspects of karst I recommend concentration to the major discipline as basics and then of course basic knowledge of related disciplines. In Germany we have now weird constructions of Biological Geology or Ecological Geology or similar combinations. This sounds holistic, considering everything. But just mixing several disciplines on a lower educational level will not contribute to major progress in science. It will merely increase the number of insignificant publications.

Are you informed with post-graduate studies of Karstology at the University of Nova Gorica held in Postojna? Would you comment it in light of your upper grades?

I know about that programme from conversations with people from the Karst Institute in Postojna. As I understand you mean the Karstology (Third level) pro- 
gramme, which comprises 3 years of doctoral study to qualify with a doctoral diploma (Dr.). It is open to people from natural science and related disciplines.

The programme is run by experts from Slovenian institutions and sometimes, as I was told, in short courses (a few weeks) by experts from abroad. Basically it is a very interesting idea to get people not only from geology but also of other disciplines of natural science together into such a programme. Slovenia is the perfect place for this because it offers spectacular karst and a wealth of opportunities for research. The studies cover a wide range of subjects as can be seen from the academic programmes in the homepage of the University of Nova Gorica. I suggest that students can also enrol to a certain extent in basic courses of physics, chemistry and mathematics, if they consider it useful.

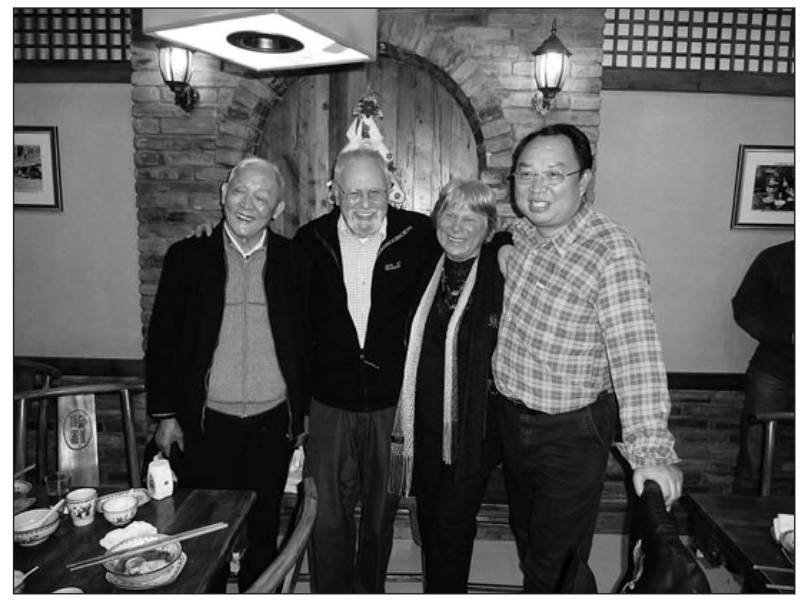

5: After a good meal in Chonqing: Left to right, Yuan Daoxian, Wolfgang Dreybrodt, Marion Dreybrodt, Liu Zaihua, December 2010.

At the present stage this programme is still in its beginning. I hope it will be successful. It combines all: people from different disciplines, international cooperation is welcome, a wide spectrum of karstology and the karst and caves of Slovenia. These are good conditions to become successful. Maybe some days in the near future this will be an important centre of karstology. My best wishes are with all, who will contribute to it. If I were a young scientist interested in karst I would consider going there.

\footnotetext{
OWN APPROACH TO KARSTOLOGY

How would you explain your personal approach to karst study?

I was fascinated by the realm of darkness in caves from which fantastic shapes emerge in the faint light on the helmet. How could such a variety of structures arise by dissolution of limestone and later by precipitation
}

of calcite? I wanted to understand the environment, which gave so much adventure admiration and satisfaction. To explore dissolution kinetics of limestone and to prove the idea of nonlinear kinetics, first proposed by Art Palmer, to explain evolution of caves was a long tedious way. But numbers were needed to get an idea, how long caves need to form and how fast stalagmites grow and which shapes they can take. And there was a further impact. Writing a book on physics and chemistry of karst was a challenge and forced me into a better understanding of the evolution and morphology of the most important features. So karst research in many ways was emotional and I was deeply impressed finding out some keys to understanding. During writing the book I got involved in the understanding of the growth and morphology of stalagmites. There were some papers of H.W. Franke and Rane Curl as a basis. These lead me to a more mathematical formulation and by pure mathematical reasoning I could show the principle of the growth of regular stalagmites. This was like a miracle. Mathematics can explain shapes of speleothems. I tried to do this also with ideally cone shaped stalactites. I failed, however. A few years ago, 2005, Short et al. from the University of Arizona, Tucson solved this problem on the basis of our work on precipitation kinetics, which shows that at film thickness lower than $100 \mu \mathrm{m}$ precipitation rates decrease. This was the key to understand the shapes of stalactites. They verified their model by observations of the shapes of many stalactites of different sizes in Kartchner Caverns State Park. I thought my work on stalagmites to be quite academic. But recently I resumed and improved it, because understanding paleo-climatic signals from oxygen and carbon isotopes needs detailed understanding on precipitation kinetics during the growth of stalagmites.

So in a way there are two replace by steps is basic science, which rests until some application revives it. The same happened in the modelling of cave evolution. The basic science was long and tedious lab work to get the basic information. Then Franci, Douchko and I explored what we could do with modelling and we found an incredible variety of ways caves can be created. Just changing a few boundary conditions causes different structures. We applied this to dam sites with steep hydraulic gradients and could show that they can be at risk. In all these attempts the karst community in various meetings and conferences supported us. In summary my own approach was emotional in both ways. Emotional in striving to understand what I saw in caves and karst terrains, and emotional in contact with colleagues, who directed me to new questions. One example is cooperation with John Mylroie in understanding how flank-margin caves form. In the Bahamas he showed me caves in Long Is- 
land, San Salvador and Eleuthera. And this was motivation for Douchko and myself to do painful, but finally successful work to understand them by modelling. At that time I met Lee Florea and learned about his work on caves in Florida. So Franci and I had an idea that this resulted from mixing corrosion, and we worked on it successfully.

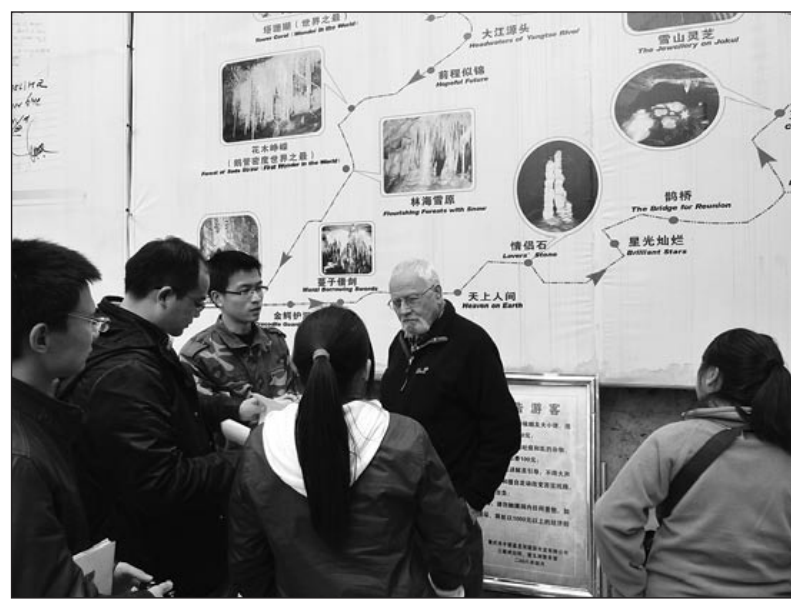

6: Wolfgang Dreybrodt in discussion with students, Chonqing, December 2010.

\section{KARSTOLOGY TODAY AND TOMOROW}

How would you assess the current situation in karstology in the world? How do you see the possibility of developing karstology as holistic science?

In 1980 karst scientists were regarded as a little bit obscure, not doing really relevant science, at least in Germany but also in other countries. I was giving a summary talk at the end of the DFG-project, which I had participated in. I got the advice to avoid the word karst, where possible, although my work on it was highly recognized. At that time there were not many connections between karst researchers, even in the western world. Nowadays this has changed. China has opened its fantastic karst landscapes, has established its own centres of karst research, and is attracting many scientists to do research in this country. The International Geoscience Programme $(I G C P)$ project with international cooperation has been important for this development.

On the other hand the need for environmental management in karst regions has attracted many engineers to explore these problems. So there are many places in the world, where work on different aspects of karst is done. At present there are many conferences where scientists can meet. And also the big geological conferences, like that of AGU/EGU present separate sessions on various aspects of karst. But all of this is science on the object karst, highly specialized at very different disciplines, as biology, geochemistry, and engineering of groundwater devices, as dam sites or prevention of saltwater intrusion. Considering stalagmites as paleo-climatic proxies has stimulated an international community with participants in all continents. They are now focusing on cave monitoring of hydrochemistry of drip water, temperature, $\mathrm{CO}_{2}$ - pressure and other parameters, which might be of interest for growth of speleothems and the isotopic signals of oxygen and carbon engraved in them.

So there are many groups working independently. I do not think that all their work can be tied to the holistic idea of karstology. Natural science poses different questions to karst as social science and there is little connection to their methods. What is important for the future is vivid exchange of concepts and results between all those who work on problems related to karst. Organisations like the IRCK in China, the Karst Research Institute in Slovenia and the Karst Water Institute, USA, are places of high importance. Institutes in Spain, France and Switzerland regularly organize conferences of increasing importance. So in the future many local activities will contribute to science in karst. Some big international organization trying to put this all together under the holistic concept of karstology is close to "religion" and will not support our science.

What do you see as a biggest interest of karstology today?

With increasing population on planet Earth the interactions between man and karst become intensified. In a recent visit to China I saw the boom of building new towns connected by modern highways, new tunnels, and bridges, all in karst areas. To sustain this and to build it needs awareness on the risks endangering such structures in karst. This applies also for dam sites. In China, rivers of $1000 \mathrm{~km}$ length with a height drop of more than $1000 \mathrm{~m}$ are terraced by dams. Also Slovenia has build new highways and railways through karst regions. These are just a few examples of many.

It is important to make the public aware of such risks by communication, telling them about karst as spectacular and beautiful natural environment, how it functions with respect to hydrology. How sinkholes can form both naturally and by impact of man. The new book Cave Geology by Art Palmer is an excellent example. Karst should be also a topic in many academic disciplines, like engineering, hydrology, geology, and biology. Not as a must but it should be offered to those, who are interested. In Germany karst science is scattered over many institutions and forms a partly isolated community with little connection to other disciplines.

I do not see any new methods at present, which will promote karst science out of itself. What we need is increasing interaction in karst research between math- 
ematics, physics, chemistry, and engineering science, which provide new means to investigate karst. Applying them to avoid hazards at the same time will increase our understanding of the properties of karst.

This is similar to what has happened in the last 30 years in the field of modelling karst processes. To employ carbonate chemistry, fluid dynamics of flow in rock and condensing this into mathematical equations has contributed much to our understanding. And it is continuing. Since 10 years European modelers meet

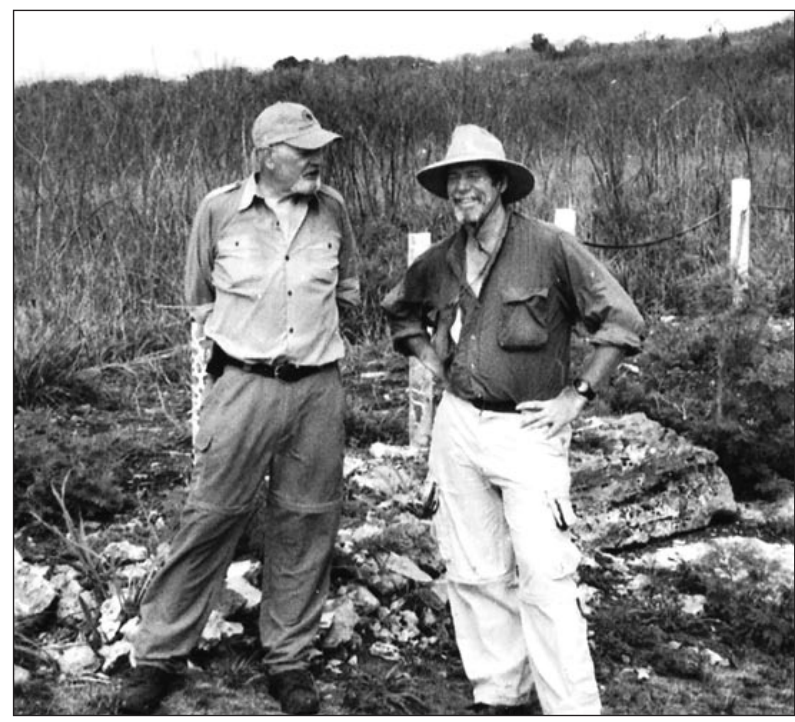

7: John Mylroie and Wolfgang Dreybrodt during excursion to flank margin caves in the Bahamas, 2004.

regularly in workshops. Georg Kaufmann and Douchko Romanov have extended the models to 3D and are revisiting some old issues to see how they might change in the more realistic 3D-models. Franci Gabrovšek has applied modelling to the evolution of caves below glaciers as they are found in Norway and has put forward recently interesting ideas about the evolution of giant collapse dolines.

\section{KARST REGIONS}

How do you see specific of karst regions and which karst regions are most attractive to you?

Historically those regions are of high interest, where people living in these areas, became interested in describing and exploring their environment. This applies to the Dinaric karst and to other regions in Europe. The Dinaric karst, being most spectacular, is an excellent example. Other karst areas worldwide remained in the dark and some are still, e.g. Laos, Mynamar and others, which have only recently been explored by cavers. The karst in South China, with its variable and fantastic morphology is an important area of research since China opened to the West.

I think one should not specify karst by regions. Dinaric karst, alpine karst, karst in Romania or Bulgaria or wherever else is karst in different geological settings and if these are similar the karst features are also to some extend.

To sculpture a karst landscape with its caves needs a lot of conditions for each specific karst region. Assume we need ten conditions, like a specific structure of rock, a sufficient amount of rainfall, deep valleys and so on. If each condition has a probability of 0.1 to occur, then the probability that all ten, which are needed to shape this particular karst landscape, are present is $10^{-10}$. This by the way answers the old question in geomorphology: Why it is here and not there?

All karst in its full variety is evolving under the rules of physics, chemistry and in some way of biology. So each karst area is of interest and ideally one should see all. So the question condenses to, since you cannot see all, which would you like most. I personally have emotionally been most attracted by tower and cone karst, alpine karst, and also by the huge caves in Kentucky.

I owe a lot to Dinaric karst, where I have a continuous and fruitful cooperation with the Karst Research Institute in Postojna, especially with Franci Gabrovšek. But I also learned a lot about karst on field trips, especially by Andrej Mihevc, with his excellent knowledge and narrative about all aspects of this karst region.

Other regions are not so spectacular, like the planes in Florida with its young porous rocks. They are also karst, which is just being recognized by the community. In the recent encyclopedias on karst and caves you do not find much about it. Recent work of Lee Florea described many small caves, isolated with no entrance and exit, which have formed differently than those in fractured rock. Flank margin caves in porous rock, e.g. in the Bahamas and now being recognized world wide, show interesting morphology. John Mylroie has been a pioneer to explore them. Here conditions are different: the rock is like sand stone with high porosity and Darcy's law governs flow. This implies that the water in the pores becomes quickly saturated with respect to calcite. Only where different waters mix in the rock, e.g. surface water from a lake seeps down the water table, dissolution is boosted by mixing corrosion. These two conditions shape entirely different features compared to mature rock, where water can flow only along fractures. So with respect to karst regions for me the most important question would be, can you find out why they are so different? This of course implies the exploration and description.

Therefore all regions, where research centres are established, will be of utmost importance. This is the 
case in Slovenia, in China and also in Spain, where some prominent Institutes organize international conferences. I hope that in future more places like these will be founded worldwide and attract researchers into these countries.

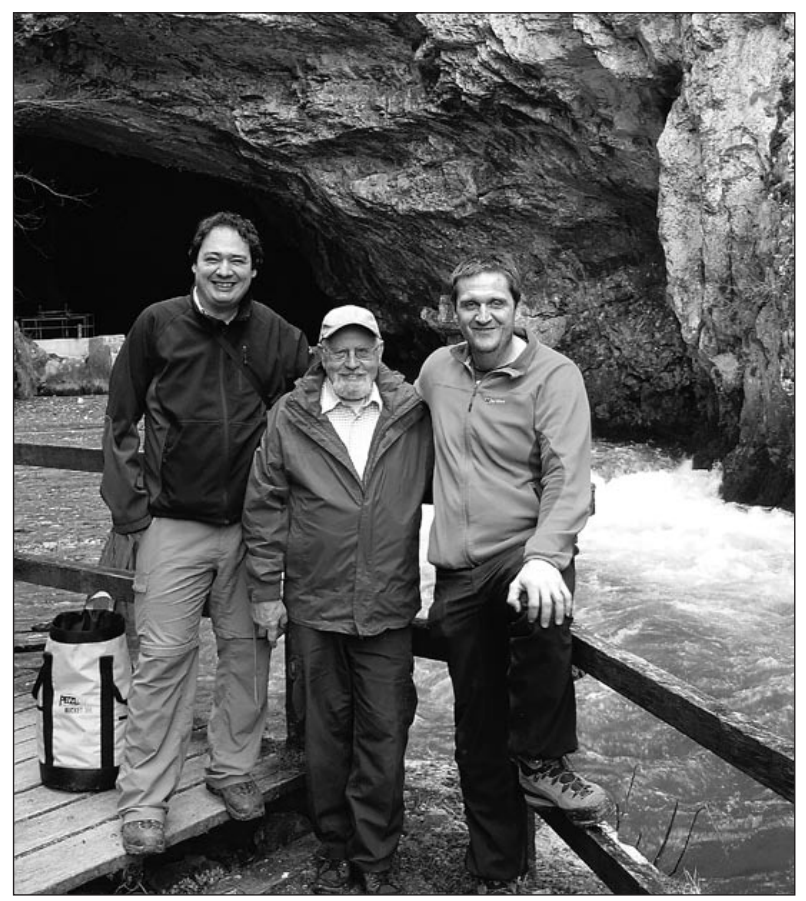

8: At the entrance of Planina Cave, April 2011. Left to right, Dushko Romanov, Wolfgang Dreybrodt, Franci Gabrovšek.

When talking on karst and caves one should not forget cavers. Which role do you think do they play in karst science?

To me they have played an extremely important role. There are many caving clubs in Germany. Their members are mostly amateurs. They have taken me into caves to show their beauty and their challenge to me. They have highly contributed to my motivation for karst science. I remember Dieter Stoffels and Bodo Schillat for many exciting trips in the caves of Sauerland and the Riesenberghöhle in the Süntel mountains. Both were engaged in all their life to communicate their knowledge and to inspire young people to caving. They are an example for many people in caving clubs worldwide who find new caves; also in regions where one supposed everything was discovered already. They survey them and produce maps. They help many scientists without much experience in caves to visit them for their scientific purposes.

This happens on all scales. In local karst areas and in international expeditions going on, which have found fantastic karst and caves in remote areas. An example is the giant cave Hang Son Doong in central Vietnam discovered by the British cavers Howard Limbert and his wife Deb. This cave has a passage of about $4 \mathrm{~km}$ length, $90 \mathrm{~m}$ wide and $180 \mathrm{~m}$ in height, interrupted by gigantic collapses.

Nowadays due to novel techniques the community of cavers has become more professional, many of them publish their findings and attract scientists to such caves.

Amateur cavers are not organized internationally. They are often individual groups and for many caving is part of their life style. There is an extreme diversity among them. Some people share results with others to mark their achievements while others just mention activities but never report their results.

But anyway, with increasing interest of biologists, climatologists, and managers for possible tourism, cavers will become the keys to visit caves and explore the scientific wealth they offer. Taken together cavers play a most important role in karstology and scientists on karst subjects should highly appreciate this. 